\title{
EFEKTIVITAS MODEL PEMBELAJARAN PROBING PROMPTING DAN NUMBERED HEADS TOGETHER (NHT) TERHADAP KEMAMPUAN BERPIKIR KRITIS
}

\section{EFFECTIVENESS OF PROBING PROMPTING AND NUMBERED HEADS TOGETHER (NHT) LEARNING MODEL TOWARDS CRITICAL THINKING}

\author{
Eva Septarina ${ }^{1}$, Sodikin ${ }^{2}$, Yahya $\mathbf{A D}^{3}$ \\ ${ }^{1,2}$ Prodi Pendidikan Fisika Fakultas Tarbiyah dan keguruan Universitas Islam Negeri Raden Intan Lampung \\ ${ }^{3}$ Prodi Bimbingan Konseling dan Pendidikan Islam Fakultas Tarbiyah dan keguruan Universitas Islam Negeri \\ Raden Intan Lampung
}

Email: septarinaeva66@gmail.com

Diterima: 28 Januari 2019. Disetujui: 20 Februari 2019. Dipublikasikan: 29 Maret 2019

\begin{abstract}
This study was conducted to find out (1) is there any influence of the probing prompting and numbered heads together learning model on students 'critical thinking abilities (2) which is the more effective learning model between the prompting and numbered heads together probing learning model on students' critical thinking skills. This research is a Quasi Experimental Design. The population in this study was all class X SMA $N 1$ Tiga Reviewed, the sampling technique was random sampling technique. The sample in this study used 2 classes, class X Mipal as the experimental class 1 and class X Mipa 2 as the experimental class 2. Testing the hypothesis using the t-test, with a significance level of 5\%. Then the effectiveness is known by the effect size test which is obtained $d=0.69$. then these results are interpreted using the table effect size, the percentage data of $73 \%$ is included in the medium category. It was concluded that (1) the probing prompting and numbered heads together learning model had a good influence on students 'critical thinking abilities (2) probing prompting and numbered heads together models were effective in improving students' critical thinking skills.
\end{abstract}

Keywords: critical thinking skills, numbered heads together, probing prompting.

Abstrak: Penelitian ini dilakukan untuk mengetahui (1) adakah pengaruh model pembelajaran probing prompting dan numbered heads together terhadap kemampuan berpikir kritis peserta didik (2) manakah model pembelajaran yang lebih efektif antara model pembelajaran probing prompting dan numbered heads together terhadap kemampuan berpikir kritis peserta didik. Penelitian ini merupakan Quasi Eksperimen Design. Populasi dalam penelitian ini adalah seluruh kelas X SMA N 1 Tiga Dihaji, Teknik pengambilan sampelnya yaitu teknik random sampling. Sampel dalam penelitian ini menggunakan 2 kelas, kelas X Mipa1 sebagai kelas eksperimen 1 dan kelas X Mipa 2 sebagai kelas eksperimen 2. Pengujian hipotesis menggunakan uji-t, dengan taraf signifikasi 5\%. Kemudian keefektifan diketahui dengan uji effect size yaitu memperoleh nilai d $=0,69$. kemudian hasil ini diinterprestasikan dengan menggunakan tabel effect size diperoleh data presentase sebesar 73\% termasuk dalam kategori sedang. Diperoleh kesimpulan bahwa (1) model pembelajaran probing prompting dan numbered heads together memberikan pengaruh yang baik terhadap kemampuan berpikir kritis peserta didik (2) model probing prompting dan numbered heads together efektif dalam meningkatkan kemampuan berpikir kritis peserta didik.

C 2018 Unit Riset dan Publikasi Ilmiah FTK UIN Raden Intan Lampung

Kata kunci: kemampuan berpikir kritis, numbered heads together, probing prompting, 


\section{PENDAHULUAN}

Sebagai individu berakal, manusia memerlukan pembelajaran untuk menjalani kehidupan. Bagi kehidupan hal mendasar dan sekaligus menjadi pembeda antara manusia dan makhluk hidup lainnya adalah pendidikan.(Anwar, 2014).Dengan demikian agar kehidupan manusia bisa berjalan dengan baik setiap manusia harus dapat memperoleh pendidikan baik itu pendidikan secara formal maupun nonformal.Perkembangan kemajuan teknologi dan keharmonisan konsep hidup dengan alam merupakan pengaruh dari cabang ilmu IPA yang kita kenal dengan fisika.(Herdianto \& Setyarsih, 2014).Pembelajaran yang harus diterapkan di SMA salah satunya pelajaran fisika, karena pada pembelajaran ini peserta didik dilatih untuk memecahkan masalah, peserta didik diberi pemahaman yang nyata tentang fakta alam dan membantu peserta didik memiliki sikap ilmiah.(Azizah, Fatmaryanti, \& Ngazizah, 2014).Dengan demikian pembelajaran fisika mampu memberikan pengalaman ilmiah bagi peserta didik dan mampu menuntut mereka untuk memecahkan masalahmasalah yang ada dikehidupan seharihari.

Biasanya pelajaran fisika dikatakan pelajaran yang susah juga membosankan, hal ini disebabkan oleh masih banyaknya guru yang bertahan menggunakan model dan metode pembelajaran klasikal, yang mana guru masih menjadi pusat dalam pembelajaran.(Sudarmini, Kosim, \& Hadiwijaya, 2015).Hasil prapenelitian yang telah dilakukan terdapat beberapa permasalahan diantaranya, masih banyak peserta didik yang memiliki kemampuan berpikir kritis yang rendah, guru belum mempunyai banyak pengetahuan dan acuan mengenai model-model yang dapat memberikan efek yang baik terhadap kemampuan berpikir kritis peserta didik.Berpikir adalah indikator kesuksesan untuk proses pembelajaran. (Wati \& Fatimah, 2016).Berpikir kritis adalah usaha membuat keputusan, menyelesaikan masalah dan menganalisis asumsi-asumsi.Santika dan hartono menyatakan bahwa salah satu modal intelektual yang sangat berguna bagi manusia untuk menuju kematangannya adalah kemampuan berpikir kritis.(Sudarmini et al., 2015).

Guru dapat mengupayakan kemampuan berpikir kritis dengan melahirkan pembelajaran agar melatih peserta didik dalam berpikir analitis untuk menentukan ketetapan dengan memakai kemampuan berpikir kritis. (Febriyanti, Yulianti, \& Sujito, 2017).Model yang membantu peserta didik dalam penyelesaian masalah dan dapat menuntun berpikir kritis adalah pembelajaran berbasis masalah. Untuk itu, suatu model kooperatif untuk menimbulkan kemampuan berpikir kritis adalah tipe Numbered Heads Together (NHT). (Wati \& Fatimah, 2016). Dan model Probing Prompting. (Rahmadi, 2016).Hasil penelitian yang sudah ada menyatakan bahwa model NHT memberikan pengaruh signifikan pada kemampuan berpikir kritis dalam pelajaran gerak lurus.(Wahyuni, 2017).Dari hasil penelitian yang lain menunjukkan keaktifan peserta didik dan kemampuan berpikir kritis matematis lebih baik setelah penggunaan model probing prompting pada pelajaran matematika. (Susanti, 2017). Penelitian ini perlu dilakukan, sebab peserta didik dituntut untuk mempunyai kemampuan berpikir kritis, dalam mempelajari materi IPA khususnya fisika sangat diperlukannya kemampuan berpikir kritis agar dapat membantu para peserta didik 
untuk bisa memahami materi dan mampu membantu menuntaskan persoalan yang mereka jumpai baik dilingkungan sekolah maupun dikehidupan sehari-hari. Untuk itu perlunya dilakukan tindak lanjut mengenai pengembangan penelitian yang mana terfokus pada kemampuan berpikir kritis akibat ditimbulkan dari model Probing Prompting dan Numbered Heads Together. Maka dari itu penelitian ini dilakukan agar dapat melihat pengaruh penerapan model Probing Prompting dan Numbered Heads Together terhadap kemampuan berpikir kritis, serta melihat perbedaan efektifitas dari penerapan model pembelajaran Probing Prompting dan Numbered Heads Together terhadap kemampuan berpikir kritis peserta didik dalam pelajaran gerak lurus.

\section{LANDASAN TEORI}

1. Hakikat Pembelajaran Fisika

Pembelajaran fisika adalah proses menciptakan kondisi dan peluang agar peserta didik dapat mengkontruksi pengetahuan, keterampilan proses dan sikap ilmiahnya. (Severinus, 2013). Pembelajaran fisika tidak dinilai dapat menguasi konsep dan mendefinisikan konsep akan tetapi fisika juga dapat membantu mengembangkan kemampuan berpikir.(Severinus, 2013).

2. Kemampuan Berpikir Kritis

Robert H. Ennis mengungkapkan bahwa berpikir kritis adalah pemikiran yang masuk akal dan reflektif yang berfokus untuk memutuskan apa yang harus dipercaya dan dilakukan.(Tawil \& Liliasari, 2013).Kemampuan berpikir kritis merupakan modal intelektual yang sangat penting bagi peserta didik.(Fisher, 2008).Kemampuan berpikir kritis sangat penting untuk melatih dan membantu peserta didik dalam mengembangkan bakatnya, melatih konsentrasi dan memfokuskan permasalahan serta berpikir
analitik.Tujuan dari berpikir kritis adalah untuk mengevaluasi tindakan terbaik atau apa yang dinyakini dan untuk mencapai pemahaman yang mendalam.

3. Model Pembelajaran

Secara keseluruhan model dimaknakan sebagai suatu objek atau konsep yang digunakan untuk merepresentasikan suatu hal. Sesuatu yang nyata dan dikonversi untuk sebuah bentuk yang lebih komprehensif.(Alatas, 2014).

Pembelajaran probing prompting adalah pembelajaran dengan menyajikan serangkaian pertanyaan yang sifatnya menuntun dan menggali gagasan peserta didik sehingga dapat melejitkan proses berpikir yang mampu mengaitkan pengetahuan dan pengalaman peserta didik dengan pengetahuan baru yang sedang dipelajari. (Huda, 2014).Langkahlangkah pembelajaran probing prompting yaitu:

Guru menghadapkan peserta didik pada situasi baru. Guru mengajukan persoalan yang sesuai dengan tujuan pembelajaran khusus atau indikator pembelajaran kepada seluruh peserta didikMenunggu beberapa saat untuk memberikan kesempatan kepada peserta didik untuk merumuskan jawaban atau melakukan diskusi kecil.Menunjuk salah satu peserta didik untuk menjawab pertanyaanJika jawabannya tepat, maka guru meminta tanggapan kepada peserta didik lain. Guru mengajukan pertanyaan akhir pada peserta didik yang berbeda

Salah satu tipe model pembelajaran kooperatif yang baik adalah Numbered Heads Together (NHT) karena menjadikan setiap siswa aktif dalam pembelajaran.(Slavin, 2009). pembelajaran kooperatif tipe NHT ini akan membuat peserta didik tidak jenuh dalam kegiatan pembelajaran dan peserta didik dapat sharing dengan teman- 
temannya untuk memecahkan permasalahan yang diberikan oleh guru,(Mulyana, Hanifah, \& Jayadinata, 2016). Tujuan dari NHT adalah memberi kesempatan kepada peserta didik untuk saling berbagi gagasan dan mempertimbangkan jawaban yang paling tepat, selain itu untuk meningkatkan kerjasama peserta didik. Langkahlangkah model pembelajaran NHT sebagai berikut:(Huda, 2014).

a. Membentuk kelompok diskusi yang beranggota 5 orang

b. Memberi nomor untuk setiap peserta didik 1- 5

c. Guru memberikan pertanyaan kepada peserta didik dan batas waktu pengerjaan

d. Masing-masing peserta didik menyampaikan pendapatnya dalam kelompok dan mendiskusikan jawaban dari pertanyaan guru

e. Setelah selesai diskusi, guru menyebutkan nomor peserta didik.

\section{METODE PENELITIAN}

Penelitian ini dilaksanakan di SMA N 1 Tiga Dihaji, Oku Selatan. Subyek pada penelitian yaitu peserta didik kelas X.Mipa tahun ajaran 2018/2019. Penelitian ini menggunkan metode Quasi Eksperimen Design.Desain penelitian yang digunakan adalah Pretest-Posttest Control Group Design. Dengan desainnya dapat dilihat pada tabel berikut:

Tabel 1. Desain penelitian Pretest-Posttes Control Group Design

\begin{tabular}{cccc}
\hline Kelas & Pretest & Perlakuan & Posttest \\
Eksperimen & $\mathrm{O}_{1}$ & $\mathrm{X}_{1}$ & $\mathrm{O}_{3}$ \\
1 & $\mathrm{O}_{2}$ & $\mathrm{X}_{2}$ & $\mathrm{O}_{4}$ \\
$\begin{array}{c}\text { Eksperimen } \\
\text { II }\end{array}$ & $\mathrm{O}$ & \\
\hline
\end{tabular}

Variabel penelitian ini terdiri atas variabel bebas $(\mathrm{X})$ dan variabel terikat (Y). variabel bebas adalah variabel yang mempengaruhi yang menjadi sebab perubahan, dipenelitian ini terdapat dua variabel bebas yaitu model pembelajaran Probing Prompting dan Numbered Heads Together (NHT). Variabel terikat adalah variabel yang dipengaruhi atau variabel menjadi akibat karena adanya variabel bebas.Variabel terikat pada penelitian ini adalah kemampuan berpikir kritis.

Populasi pada penelitian ini yaitu peserta didik kelas X.Mipa SMA Negeri 1 Tiga Dihaji, Semester ganjil, tahun ajaran 2018.Sampel pada penelitian ini yaitu peserta didik kelas X.Mipa1 dan X.Mipa2 SMA Negeri 1 Tiga Dihaji.Teknik pengambilan sampel pada penelitian ini yaitu dengan teknik random sampling.

Pada penelitian ini data didapat dengan beberapa metode pengumpulan data yaitu tes kemampuan berpikir kritis, dokumentasi dan observasi. Instrumen yang telah disusun kemudian diuji dengan menggunakan:

1. Uji Validitas

Instrumen dikatakan valid jika memiliki kesejajaran antara hasil dengan apa yang diukur. Untuk mengetahui validitas soal digunakan rumus.

$\mathrm{r}_{\mathrm{xy}}=\frac{N \sum X Y-\left(\sum X\right)\left(\sum Y\right)}{\sqrt{\left[N \sum X^{2}-\left(\sum X\right)^{2}\right]\left[N \sum Y^{2}-\left(\sum Y\right)^{2}\right]}}$

Bila $r_{x y}$ di bawah 0,30, maka dapat disimpulkan bahwa butir instrumen tersebut tidak valid, sehingga harus diperbaiki atau dibuang(Sugiyono, 2015).

2. Uji Reliabilitas

Untuk menentukan tingkat reliabilitas tes digunakan metode satu kali tes dengan teknik Alpha. Perhitungan uji reliabilitas dengan menggunakan rumus alpha,(Arikunto, 2013). yaitu :

$\mathrm{r}_{11}=\left(\frac{n}{n-1}\right)\left(1-\frac{\sum \sigma i^{2}}{\sigma t^{2}}\right)$

3. Uji Daya Pembeda 
Daya pembeda adalah untuk menentukan dapat tidaknya suatu soal membedakan kelompok dalam aspek yang diukur sesuai dengan perbedaan yang ada dalam kelompok itu. Indeks daya pembeda dapat dicari dengan menggunakan rumus sebagai berikut (Arifin, 2008):

$\mathrm{DP}=\frac{\bar{X} K A-\bar{X} K B}{\text { Skor Maks }}$

4. Uji Tingkat Kesukaran

Menghitung tingkat kesukaran butir tes digunakan rumus(Arifin, 2008):

Tingkatkesukaran $=\frac{\text { rata-rata }}{\text { skor } \text { maks tiap soal }}$

Tingkat Kesukaran soal dapat dikategorikan sebagai berikut:

Tabel 2. Tingkat Kesukaran Soal

\begin{tabular}{cc}
\hline Nilai (p) & Kategori \\
$\mathrm{P}<0,3$ & Sukar \\
$0,3 \leq \mathrm{p} \leq 0,7$ & Sedang \\
$\mathrm{P}>0,7$ & Mudah \\
\hline
\end{tabular}

Data penelitina kemudian dianalisis dengan langkah sebagai berikut:

1. Gain Ternormalisasi

Gain adalah selisih antara nilai posttest dan pretest, nilai gain menunjukkan peningkatan hasil belajar fisika peserta didik setelah pembelajaran yang dilakukan oleh guru. Gain yang dinormalize (N-gain) dapat dihitung dengan persamaan:

$$
N \text {-gain }=\frac{\text { skor posttest }- \text { skor pretest }}{\text { skor ideal-skor pretest }}
$$

Klasifikasi $N$-gain ternormalisasi menurut Richard R Hake dapat diklasifikasikan sebagai berikut:

Tabel3.Klasifikasi Tingkat N-gain

\begin{tabular}{cc}
$\begin{array}{c}\text { Kategori Nilai N- } \\
\text { gain }\end{array}$ & Kriteria \\
N-gain $>70$ & Tinggi \\
$0,30 \leq \mathrm{N}$-gain $\leq$ & Sedang \\
0,70 & \\
N-gain $<0,30$ & Rendah \\
\hline
\end{tabular}

(Fayakun, M \& Joko, 2015).

2. Uji Normalitas
Perhitungan uji normalitas data, digunakan uji Lilliefors. "Pegujian normalitas data dengan uji Lilliefors dilakukan dengan membandingkan data obseravasi dengan frekuensi sebaran data yang sudah berdistribusi normal.(Wati \& Fatimah, 2016).Uji Liliefors merupakan salah satu uji yang sering digunakan untuk menguji kenormalan data.

3. Uji Homogenitas

Untuk mengetahui kesamaan antar dua keadaan maka menggunakan uji homogenitas, uji homogenitas yang dipakai yaitu uji fisher (Wati \& Fatimah, 2016).

4. Uji t

Untuk menghitung Uji $t$ dapat menggunakan rumus, (Anas, 2012):

5. Uji Effect Size

$$
\mathrm{t}=\frac{M_{x}-M_{y}}{\sqrt{\left[\frac{\sum x^{2}+\sum y^{2}}{n_{1}+n_{2}-2}\right]\left(\frac{n 1+n 2}{n 1 x n 2}\right)}}
$$

Analisis data untuk mengetahui efektifitas penggunaan model pembelajaran probing Prompting dan Numbered Heads Together (NHT) terhadap kemampuan berpikir kritis peserta didik pada materi gerak lurus, maka menggunakan rumus Effect Size.

6. Uji Hasil Observasi

Data dari hasil observasi diukur dengan menggunakan skala likert(Sugiyono, 2015):

\section{HASIL DAN PEMBAHASAN}

Penelitian tersebut dilakukan di SMA N 1 Tiga Dihaji, Oku selatan selama kurang lebih 1 bulan. Penelitian dilakukan dengan menerapkan dua model pembelajaran pada dua sampel kelas eksperimen yang mana pada kelas eksperimen 1 diterapkan model Probing Prompting sedangkan kelas eksperimen 2 dengan model Numbered Heads Together (NHT).Penelitian ini bertujuan untuk melihat pengaruh model probing 
prompting dan numbered heads together pada kemampuan berpikir kritis peserta didik khusunya pelajaran gerak lurus dan untuk melihat model mana yang lebih efektif digunakan antara model pembelajaran probing prompting dan numbered heads together pada

Tabel.4. Hasil Pretest dan Posttest Kemampuan Berpikir Kritis Peserta Didik

\begin{tabular}{ccccc}
\hline \multirow{2}{*}{ Perolehan } & \multicolumn{2}{c}{ Pretest } & \multicolumn{2}{c}{ Posttest } \\
& PP & NHT & PP & NHT \\
\hline Nilai Minimum & 30 & 30 & 70 & 70 \\
Nilai Maksimum & 45 & 45 & 77.5 & 80 \\
Rata-rata & 37.6 & 37.05 & 74.2 & 76.25 \\
Kategori & Kurang baik & Kurang baik & Baik & Baik \\
\hline
\end{tabular}

Dari data di atas diketahui rata-rata nilai pretest danposttest kelas probing prompting dan kelas NHT mengalami kemajuan. Pada kelas probing prompting rata-rata nilai pretest sebesar 37.6 setelah diberi perlakuan nilai postest meningkat menjadi 74.2 , sedangkan pada kelas NHT rata-rata nilai pretestnya sebesar 37.05 setelah diberi perlakuan nilai kemampuan berpikir kritis khususnya pelajaran gerak lurus. Berikut hasil tes akhir kemampuan berpikir kritis peserta didik.

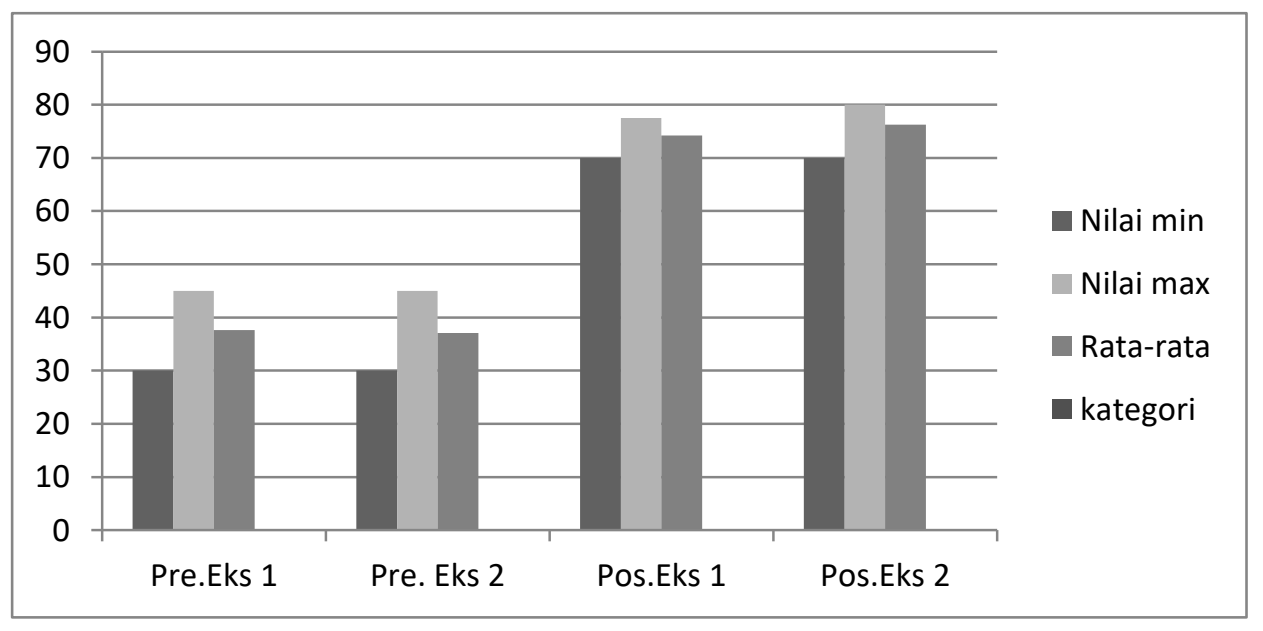

Gambar 1.Grafik Hasil Tes Kemampuan Berpikir Kritis Peserta Didik Kelas Probing Prompting dan NHT. 
Tabel 5 Hasil Uji N-gain Kemampuan Berpikir Kritis Kelas Probing Prompting dan Kelas NHT

\begin{tabular}{ccccc}
\hline \multirow{2}{*}{ Komponen } & \multicolumn{2}{c}{ Kelas Probing Prompting } & \multicolumn{2}{c}{ Kelas NHT } \\
& Pretest & posttest & pretest & Posttest \\
\hline Skor minimum & 30 & 70 & 30 & 70 \\
Skor maksimum & 45 & 77.5 & 45 & 80 \\
Rata-rata & 37.6 & 74.2 & 37.05 & 76.25 \\
Rata-rata N-Gain & \multicolumn{2}{c}{0.58 (Sedang) } & \multicolumn{2}{c}{0.62 (Sedang) } \\
\hline
\end{tabular}

Dari tabel di atas diperoleh nilai $n$ gain kelas Probing prompting sebesar 0.58 , sedangkan kelas NHT memperoleh nilai $n$-gain sebesar 0.62 .Ini membuktikan bahwa model pembelajaran numbered heads together lebih efektif digunakan dalam menumbuhkan kemampuan berpikir kritis daripada model probing prompting pada materi gerak lurus kelas $\mathrm{X}$ SMA Negeri 1 Tiga Dihaji.

Analisis data penelitian dilakukan dengan uji yakni uji normalitas, uji homogenitas, uji hipotesis dan uji effect size. Hasil uji normalitas yang dilakukan pada nilai posstest di kedua kelas eksperimen dengan taraf signifikan sebesar 0.05 , diperoleh $\mathrm{L}_{\text {hitung }}<\mathrm{L}_{\text {tabel }}$ yaitu $0.165<0.189$ hasil ini menunjukkan bahwa data terdistribusi normal.Sedangkan hasil uji hogenitas pada kedua kelas memperoleh hasil $\mathrm{F}_{\text {hitung }}<\mathrm{F}_{\text {tabel }}$ yaitu $0.50<2.04$ ini berarti data terdistribusi homogen. Setelah data normal dan homogen dilanjutkan uji hipotesis dengan uji-t memperoleh hasil $t_{\text {hitung }}>t_{\text {tabel }}$ yaitu 2.14>2.02 ini berarti Ho ditolak dan H1 diterima dan disimpulkan bahwa model probing prompting dan numbered heads together berpengaruh terhadap kemampuan berpikir kritis peserta didik dalam materi gerak lurus. Kemudian untuk melihat keefektifan dari kedua model dilakukan uji effect size dan diperoleh hasil $\mathrm{d}=0.69$ masuk dalam kriteria sedang. Dari uji effect size ini diketahui bahwa model probing prompting dan numbered heads together efektif terhadap kemampuan berpikir kritis.

Dari hasil penelitian yang dilakukan memang membuktikan bahwa model pembelajaran probing prompting mampu memberikan pengaruh yang baik terhadap kemampuan berpikir kritis peserta didik karena dalam pembelajaran ini peserta didik diajak untuk memecahkan dan mencari solusi dari permasalahan yang diberikan, selain itu pada pembelajaran ini peserta didik bisa mendapatkan pengetahuan baru mengenai pembelajaran dan peserta didik juga dilatih dan dituntun untuk berpikir dan menemukan solusi dan jawaban terbaik dari soal-soal yang diajukan. Model pembelajaran numbered heads together juga memberikan pengaruh yang sangat baik terhadap kemampuan berpikir kritis peserta didik, karena pada proses pembelajarannya model ini menuntut peserta didik untuk aktif dan berpikir kritis dalam pembelajaran kelompok, mulai dari mengidentifikasi masalah merumuskan hipotesis,mendiskusikan, menyimpulkan masalah, mengevalusi, dan memberikan solusi. Selain itu peserta didik bisa saling bertukar ide, gagasan, serta bisa saling membelajarkan antar peserta didik, kerja sama dan kekompakan juga bisa tercipta dalam pembelajaran, rasa tanggung jawab dengan kelompok juga bisa diperoleh.Pembelajaran ini mampu membuat para peserta didik untuk bisa berpikir kritis dalam setiap memecahkan masalah yang diberikan oleh guru. 
KESIMPULAN DAN SARAN

Model pembelajaran Probing
Prompting dan Numbered Heads Together(NHT) memberikan pengaruh yang baik terhadap kemampuan berpikir kritis peserta didik, dan kedua model efektif untuk meningkatkan kemampuan berpikir kritis, dilihat dari nilai rata-rata $N$-gain model NHT lebih efektif dibandingkan model Probing Prompting dalam mempengaruhi kemampuan berpikir kritis peserta didik.

Untuk penelitian lebih lanjut bisa menggunakan kedua model ditambah dengan media pembelajaran yang tepat untuk membantu peserta didik untuk lebih cepat memahami pembelajaran dan lebih bisa melatih kemampuan berpikir kritis.

\section{DAFTAR PUSTAKA}

Alatas, F. (2014). Hubungan Pemahaman Konsep dengan Keterampilan Berpikir Kritis Melalui Model Pembelajaran Treffinger pada Mata Kuliah Fisika Dasar. Edusains, 6(1).

Anas, S. (2012). Pengantar Statistik Pendidikan. jakarta: Rajawali Pers.

Anwar, C. (2014). Hakikat Manusia dalam Pendidikan (Sebuah Tinjauan Filosofis). Yoyakarta: SUKA- Press.

Arifin, Z. (2008). Dasar-Dasar Penulisan Karya Ilmiah, Edisi Keempat. Jakarta: Grasindo.

Arikunto, S. (2013). Prosedur Penelitian Suatu Pendekatan Praktik.

Azizah, N., Fatmaryanti, S. D., \& Ngazizah, N. (2014). Penerapan Model Pembelajaran Konstruktivisme Berbasis Problem Based Learning ( PBL ) Untuk Meningkatkan Kemampuan Berfikir Kritis Pada Siswa SMA Negeri 1 Kutowinangun Kelas $\mathrm{X}$ Tahun Pelajaran 2013 / 2014. Jurnal Radiasi, 5(2).
Fayakun, M, \& Joko, P. (2015). Efektivitas Pembelajaran Fisika Menggunakan Model Kontekstual (CTL) dengan Metode Predict, Observe, Explain terhadap Kemampuan Berpikir Tingkat Tinggi. Jurnal Pendidikan Fisika Indonesia, 11(1).

Febriyanti, N. A., Yulianti, L., \& Sujito. (2017). Pengaruh Authentic Problem Based Learning (APBL) Terhadap Kemampuan Berpikir Kritis Mahasiswa Prodi Pendidikan Fisika Universitas Negeri Malang. Jurnal Jurusan Fisika, FMIPA , Universitas Negeri Malang, 22(1).

Fisher, A. (2008). Sebuah Pengantar Berpikir Kritis. Jakarta: Erlangga.

Herdianto, H., \& Setyarsih, W. (2014). Identifikasi Profil Berpikir Kritis Siswa dalam Pembelajaran Fluida Statis dengan Modifikasi High - $\alpha$ Binaural Beats dan Guided Problem Solving. 03(02).

Huda, M. (2014). Model-model Pengajaran dan pembelajaran: Isuisu Metodis dan Paradigma. Yogyakarta: Pustaka Pelajar.

Mulyana, M. A., Hanifah, N., \& Jayadinata, A. K. (2016). Penerapan Model Kooperatif Tipe Numbered Heads Together ( NHT ) Untuk Meningkatkan Hasil Belajar Siswa Pada Materi Kenampakan Alam Dan Sosial Budaya. Jurnal Pena Ilmiah, 1(1).

Rahmadi, T. N. (2016). Pengaruh Penerapan Metode Probing Prompting pada Pembelajaran IPA SMP Kelas VII Terhadap Kemampuan Berpikir Kritis Siswa. Jurnal Pendidkan Matematika Dan Sains, 2(3).

Severinus, D. (2013). Pembelajaran Fisika Seturut Hakekatnya Serta 
Sumbangannya dalam Pendidikan Karakter Siswa. Seminar Nasional 2nd Lontar Physics Forum.

Slavin, R. . (2009). Cooperatif Learning: Teori, Riset dan Praktik. Bandung: Nusa Media.

Sudarmini, Y., Kosim, \& Hadiwijaya, A. S. (2015). Pembelajaran Fisika Berbasis Inkuiri Terbimbing dengan Menggunakan LKS Untuk Meningkatkan Keterampilan Berpikir Kritis Ditinjau dari Sikap Ilmiah Siswa Madrasah Aliyah Qamarul Huda Bagu Lombok Tengah. Jurnal Penelitian Pendidikan IPA (JPPIPA), 1(1).

Sugiyono. (2015). Metode Penelitian Pendidikan Pendekatan Kuantitatif, Kualitatif, dan $R$ \& D. Bandung: Alfabetha.

Susanti, E. (2017). Penerapan Model Pembelajaran Probing Prompting Untuk Meningkatkan Kemampuan Berpikir Kritis Matematis Siswa Kelas XI. IPA MAN 1 Kota Bengkulu. Jurnal Pendidikan Matematika Raflesia, 2(1).

Tawil, M., \& Liliasari. (2013). Berpikir Kompleks dan Implementasi dalam Pembelajaran Fisika. Makassar: Badan Penerbit UNM.

Wahyuni, S. R. I. (2017). JURNAL PENGARUH MODEL PEMBELAJARAN NHT ( NUMBERED HEADS TOGETHER ) TERHADAP KEMAMPUAN BERFIKIR KRITIS SISWA PROGRAM STUDI PENDIDIKAN MATEMATIKA PERNYATAAN SURAT SKRIPSI TAHUN 2017. Jurnal Pendidikan Matematika Universitas Nusantara PGRI Kediri.

Wati, W., \& Fatimah, R. (2016). Effect Size Model Pembelajaran Kooperatif
Tipe Numbered Heads Together (NHT) terhadap Kemampuan Berpikir Kritis Siswa pada Pembelajaran Fisika. Jurnal Ilmiah Pendidikan Fisika Al-Biruni, 5(2). 